\title{
Letter: what is new about triticeal cartilage?
}

\author{
Alper Vatansever (iD \\ Department of Anatomy, Faculty of Medicine, Balkesir University, Balıkesir, Turkey \\ Anatomy 2020;14(3):231 @2020 Turkish Society of Anatomy and Clinical Anatomy (TSACA)
}

\section{Dear Editor,}

I would like to make comments and contributions to the article about the triticeal cartilage conducted by Koca et al. ${ }^{[1]}$ I have read this study with great interest and curiosity.

Koca et al ${ }^{[1]}$ aimed to investigate prevalence of the triticeal cartilage with its morphometric properties such as length, width and shape. There are some examples focusing on same purpose with different methods. ${ }^{[2]]}$ The number of participants included the current study seems lower than other prevalence studies. Increasing participant number may be beneficial for improving the strength of study.

Koca et al. ${ }^{[1]}$ aimed to evaluate morphometric properties of the triticeal cartilage. The authors completed length and width measurements, and recorded the distribution of cartilage shapes to achieve this purpose. Alqahtani et al.$^{[3]}$ was the first to describe variable shapes of the triticeal cartilage. Then, Vatansever et al. ${ }^{[4]}$ reported another study based on Alqahtani's classification. Koca et al. ${ }^{[1]}$ used similar classification system but have described three new shapes of the cartilage; hook, double circle and ring. Describing those new shapes makes a great contribution to the current literature. Since those shapes were described for the first time by Koca et al., ${ }^{[1]}$ a clear description of those shapes may be required to avoid misdiagnosis with pathologies which could appear in that region, such as atherosclerosis. However, calcification status of the triticeal cartilage was not mentioned in this study. The triticeal cartilages may or may not calcified. When they calcified, the calcification pattern could demonstrate differences between individuals.
Calcification could begin from outside of the cartilage and continue to its center or vice versa. Calcification situation of this cartilage may affect its appearance on radiologic images. For example, definition of double ring shaped triticeal cartilage could be better explained in more details. Does it mean that there were two different triticeal cartilages on one side or the cartilage began to calcify in a different way? Detailed definition for hook and ring shaped triticeal cartilage is also needed for same concerns.

As conclusion, strength of the study can be improved with clear explanation of new anatomical or clinical facts of the triticeal cartilage. Especially, completing evaluation of calcification status would make the impact of the study stronger. I hope Koca et al. ${ }^{[1]}$ get those opinions positively and improve their further studies about the triticeal cartilage with these aspects.

\section{References}

1. Koca R, Fazlığulları Z, Kelesoğlu KS, Kolpay M, Karabulut AK. Prevalence and clinical significance of the triticeal cartilage. Anatomy 2020;14:97-101.

2. Ahmad M, Madden R, Perez L. Triticeous cartilage: prevalence on panoramic radiographs and diagnostic criteria. Oral Surg Oral Med Oral Pathol Oral Radiol Endod 2005;99:225-30.

3. Alqahtani E, Marrero DE, Champion WL, Alawaji A, Kousoubris $\mathrm{PD}$, Small JE. Triticeous cartilage CT imaging characteristics, prevalence, extent, and distribution of ossification. Otolaryngol Head Neck Surg 2016;154:131-7.

4. Vatansever A, Demiryurek D, Tatar I, Ozgen B. The triticeous cartilage - redefining of morphology, prevalence and function. Folia Morphol (Warsz) 2018;77:758-63.
ORCID ID:

A. Vatansever 0000-0002-3632-1020
Correspondence to: Alper Vatansever, PhD

Department of Anatomy, Faculty of Medicine, Ballkesir University, Ballkesir, Turkey Phone: +90266 6121010 - 216874

e-mail: alpervatansever@yahoo.com

Conflict of interest statement: No conflicts declared.

This is an open access article distributed under the terms of the Creative Commons Attribution-NonCommercial-NoDerivs 4.0 Unported (CC BY-NC-ND4.0) Licence (http://creativecommons.org/licenses/by-nc-nd/4.0/) which permits unrestricted noncommercial use, distribution, and reproduction in any medium, provided the original work is properly cited. How to cite this article: Vatansever A. Letter: what is new about triticeal cartilage? Anatomy 2020;14(3):231. 